\title{
FIELD TEST AND NUMERICAL MODELLING OF RC SLABS AT DIFFERENT SCALED DISTANCES WITH TWO TYPES OF EXTERNAL REINFORCEMENT
}

\author{
SANTIAGO MARTÍNEZ-ALMAJANO ${ }^{1,2}$, RICARDO CASTEDO ${ }^{1}$, LINA M $^{\mathrm{a}}$ LÓPEZ $^{1}$, \\ ANASTASIO P. SANTOS ${ }^{1}$, MARÍA CHIQUITO $^{1}$, ALEJANDRO ALAÑÓN $^{3}$ \& CARLOS REIFARTH ${ }^{1}$ \\ ${ }^{1}$ ETSI Minas y Energía, Universidad Politécnica de Madrid, Spain. \\ ${ }^{2}$ Escuela Politécnica Superior del Ejército, Spain. \\ ${ }^{3}$ Escuela Politécnica Superior de Ávila, Universidad de Salamanca, Spain.
}

\begin{abstract}
This work deals with the response of eight reinforced concrete (RC) slabs, made at full-scale, some of them with the addition of externally bonded fibre reinforced polymer (FRP). The reinforcements were placed in all cases on the face opposite to the explosive detonation. Three scaled distances have been used from $0.83 \mathrm{~m} / \mathrm{kg}^{1 / 3}$, in one test with no extra reinforcement; four tests were made with a scaled distance of $0.42 \mathrm{~m} / \mathrm{kg}^{1 / 3}$ : one without extra reinforcement, two with carbon fibre reinforcement (CFRP) and one with the E-glass fibre reinforcement (GFRP); finally, $0.21 \mathrm{~m} / \mathrm{kg}^{1 / 3}$, in three trials, one without extra reinforcement, one with carbon fibre reinforcement and one with the E-GFRP. The first slab, used for calibration of the numerical models, was instrumented with pressure and acceleration sensors. For the validation of the other seven slabs, the damage surfaces on both sides of the slabs are used. In terms of numerical simulation performed with LS-DYNA, several models covering different solutions such as smooth particle hydrodynamics (SPH) or load blast enhanced have been performed for the description of the explosive, as well as the use of CSCM material models for concrete to analyse the best available solutions. The steel was modelled with the piecewise linear plasticity material, while the material laminated composite fabric was used for the FRP. Reinforcement with CFRP resulted in a generally reduced damage area on both surfaces. All models show a good correlation, including nonspherical charges made with SPH models, with the test results when comparing them with respect to acceleration and surface damage. SPH models work well for the high and medium scaled distance, but not so good for the shorter scaled distance.
\end{abstract}

Keywords: explosive, FEM simulation, full-scale tests, slabs.

\section{INTRODUCTION}

Intentional detonations near historic structures and vital infrastructure demonstrate the importance of fully comprehending the potential consequences. To do so, a thorough understanding of the size and distribution of the blast load, as well as the response of a structure subjected to this charge, is needed to enhance blast protection systems or designs [1]. There are numerous studies on structural elements such as beams [2], slabs [3], brick and precast concrete walls [4-5], etc., but not so many on a complete structure or on several structural elements working as a unit [6]. This is particularly significant in recent years, as many studies are focused on numerical models without real models to validate them or, in the best cases, use field data from others due to budget constraints [7]. Furthermore, most authors used small (scaled) specimens because full (real)-scale experiments are costly, difficult to manage and track, and difficult to simulate [8]; however, the scale factor may have a significant influence. 
There are different numerical approaches to the problem, as well as various software's such as LS-DYNA [9] or AUTODYN [10]. Regarding the possible numerical approaches, it should be noted that the approach is usually determined by the characterisation or description of the explosive charge. The most commonly used models are the classical load blast enhanced (LBE), based on the work made by [11], usually employed in Lagrangian models; the Multi-Material Arbitrary Lagrangian-Eulerian (MM-ALE) based on the explicit description of the explosive charge with a fundamentally Eulerian model, which requires equation of state (EOS) for the charge or its TNT equivalent; the combination of both where the explosive charge up to a point is treated as LBE and from there the airwave is 'moved' through the air grid; and the mesh-free models such as smooth particle hydrodynamics (SPH) and particle blast method, in both cases the explosive charge is described and modelled explicitly, but in the former, the charge is described as an explosive, and in the latter, it is described as an ideal gas, with the limitations that this entails.

In this paper, simulations of full-scale tests of concrete slabs are presented using the LBE and SPH techniques for blast loading but using a Lagrangian formulation for the slabs. The software LS-DYNA (version 971-R10) has been used for the simulations.

\section{EXPERIMENTAL TESTS}

The tests were carried out during 2019 at the Technological Institute of 'La Marañosa' belonging to the National Institute of Aerospace Technology (INTA). Each reinforced concrete (RC) slab was tested in an individual test; therefore, eight different trials had to be performed. In three of those tests, the slab had no extra reinforcement (S1, S2 and S7), but loads and distances were varied to have a comparison pattern; however, carbon and glass fibres (CF and GF, respectively) were tested at two distances, but always with the same load. See Table 1 for more details.

The reinforcement (steel B-500 S) was constructed with 10-mm bars spaced $300 \mathrm{~mm}$ apart in both directions on the blast face, while on the opposite face, the bars were $12 \mathrm{~mm}$ spaced $150 \mathrm{~mm}$ apart in both directions. The concrete and steel characteristics are detailed in the numerical model section.

The test with scaled distance equal to $0.83 \mathrm{~m} / \mathrm{kg}^{1 / 3}$ was instrumented with pressure and acceleration sensors for comparison with the numerical models. The details can be seen in Fig. 1. Due to problems with the measuring or data acquisition equipment, data were only recorded on sensors $\mathrm{P} 1$ and $\mathrm{A} 2$.

Table 1: Characteristics of the tests. Charge height over the slab.

\begin{tabular}{lllll}
\hline Test \# & Reinforcement & $\begin{array}{l}\text { Scaled distance } \\
{\left[\mathbf{m} / \mathbf{k g}^{\mathbf{1} 3}\right]}\end{array}$ & $\begin{array}{l}\text { Eq. mass TNT } \\
{[\mathbf{k g}]}\end{array}$ & $\begin{array}{l}\text { Charge height } \\
{[\mathbf{m}]}\end{array}$ \\
\hline S1 & None & 0.83 & 1.74 & 1 \\
S2 & None & 0.21 & 13.05 & 0.5 \\
S3 & Glass & 0.21 & 13.05 & 0.5 \\
S4 & Carbon & 0.21 & 13.05 & 0.5 \\
S5 & Glass & 0.42 & 13.05 & 1 \\
S6/S8 & Carbon & 0.42 & 13.05 & 1 \\
S7 & None & 0.42 & 13.05 & 1 \\
\hline
\end{tabular}



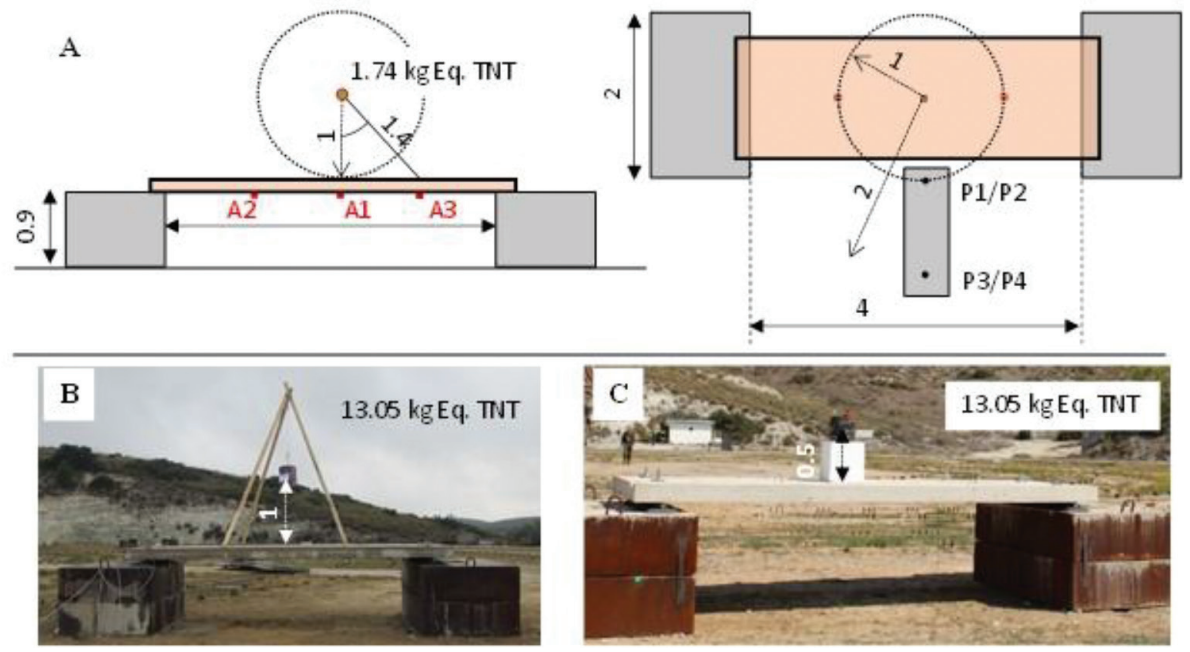

Figure 1: General test set-up with units in meters. A) Details of the test S1, B) details of the test S7 (photograph), S5 and S6/S8 and C) details of the test S2 (photograph), S3 and S4.

The explosive used was dynamite, with a TNT equivalent of 0.87 calculated following the methodology proposed by Chiquito et al. [12] based on data provided by the UFC [13]. The load used in these tests could be classified according to the UFC as spherical when we have $1.74 \mathrm{~kg}$ of Eq. TNT or as intermediate between bag, cylindrical and cube when having 13.05 $\mathrm{kg}$ of Eq. TNT. In all cases, the charge is initiated from the centre with a detonator.

\section{NUMERICAL MODEL}

As mentioned, the use of numerical models is becoming increasingly widespread in the defence and explosives research. Their use saves testing costs and enables a greater number of results to be obtained in reasonable times. In this case, all the models made are in 3D and at real scale, as in the tests described.

The concrete, in both cases LBE and SPH, was implemented with the Continuous Surface Cap Model (MAT_159-CSCM_concrete) and generated with 3D solid elements solved with reduced integration. This model works with reduced data input [14], and it is sufficient to define the density $\left(2300 \mathrm{~kg} / \mathrm{m}^{3}\right)$, the simple compressive strength $(25 \mathrm{MPa})$, the maximum aggregate size $(0.02 \mathrm{~m})$ and the numerical parameter that controls the erosion of the aggregate (known as ERODE). This last parameter has been left at its default value of 1.05 [15]. Prior to cracking, this elasto-plastic damage model exhibits isotropic elastic behaviour, after which the material exhibits a plastic behaviour restricted by the failure surfaces. An element can be eroded when the scalar damage parameter is greater than or equal to 0.99 , and the maximum principal strain in the element exceeds the ERODE value.

The steel, introduced into the model with the MAT_24-PIECEWISE_LINEAR_PLASTICITY, has been described with beam elements. This model uses an elasto-plastic description with a failure based on an effective plastic strain, equal to 0.15 in this case. The stress strain behaviour has been handled with a bilinear stress strain curve by specifying the tangent modulus. The properties based on the standard RC 1247/2008 - EHE-08 national design code based on EN-1992 [16] are the density $\left(7850 \mathrm{~kg} / \mathrm{m}^{3}\right)$, yield strength (500 MPa), Young's 
modulus (200 GPa), Poisson's ratio (0.3) and tangent modulus (20 GPa). See Castedo et al. [17] for more details.

Given the speed at which the explosive phenomenon takes place, we can consider that the concrete and the steel act as a unit, to reproduce this behaviour the command chosen in LS-DYNA was *Constrained_Lagrange_in_Solid. Since the mesh size affects every Lagrangian model, a convergence analysis should be performed before beginning the calculations. The element sizes of concrete (solids) and bars (beams) were $18 \times 18 \times 18 \mathrm{~mm}$ and 50 $\mathrm{mm}$ thickness, respectively, after this study and considering previous works by the authors $[3,17,18]$.

Both fibre reinforced polymer (FRP) reinforcements have been simulated using the *MAT_058-MAT_LAMINATED_COMPOSITE_FABRIC model, with shell-type elements. The model is based on Hasin's [19] rupture criterion and selecting a smooth failure surface from the four available options. The model also requires an erosion parameter (ERODS), which has been calibrated and is equal to -0.55 . See the work by Reifarth [20] for more details. The properties of the FRP used can be found in Table 2.

\subsection{Blast implementation}

As mentioned in the introduction section, two possibilities exist when describing the explosive charge.

The first one is to define the charge explicitly, which requires the geometry of the charge and the EOS to calculate the detonation expansion products. This first option requires a mesh-free numerical method, such as SPH. In our case, and since the EOS for dynamite is unknown, we will use the equivalent TNT charge and describe the charge as if it were a TNT. The EOS used is the Jones-Wilkins-Lee or as it is commonly known JWL. The values for this equation are those taken from Dobratz and Crawford [21]. Values for density (1630 kg/ $\mathrm{m}^{3}$ ), detonation velocity $(6930 \mathrm{~m} / \mathrm{s}$ ) and pressure at the Chapman-Jouguet point (21 GPa, also known as $\mathrm{P}_{\mathrm{CJ}}$ ) have also been obtained from the same source. As mentioned, the small charge (1.74 kg of TNT Eq.) has been modelled as a sphere; however, the bigger charge cannot be classified in one type following the UFC [13], so three different models have been done: cylindrical, cube or bag. See Fig. 2 for more details.

In the most used case such as LBE, the data required are simpler and include the equivalent TNT mass, the coordinates of the centre of the charge (it is implemented only for

Table 2: Carbon and glass FRP properties.

\begin{tabular}{llll}
\hline Property & Units & Carbon & Glass \\
\hline Density & $\mathrm{kg} / \mathrm{m}^{3}$ & 1830 & 2000 \\
Young modulus & $\mathrm{GPa}$ & 252 & 42 \\
Poisson's ratio & - & 0.3 & 0.285 \\
Shear modulus & $\mathrm{GPa}$ & 4.8 & 3.9 \\
Elongation at failure & $\%$ & 1.8 & 4 \\
Tensile strength, principal direction & $\mathrm{GPa}$ & 2.93 & 1.62 \\
Compression strength, principal direction & $\mathrm{GPa}$ & 0.298 & 0.1129 \\
In-plane shear strength & $\mathrm{GPa}$ & 0.0845 & 0.0308 \\
\hline
\end{tabular}


A

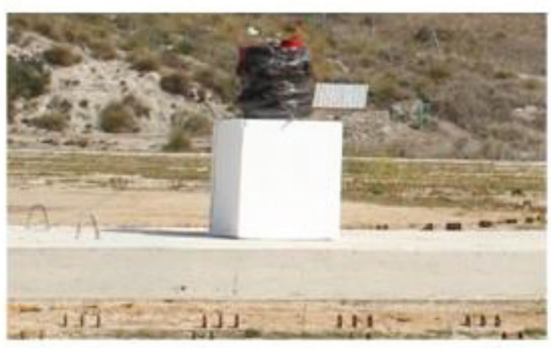

C
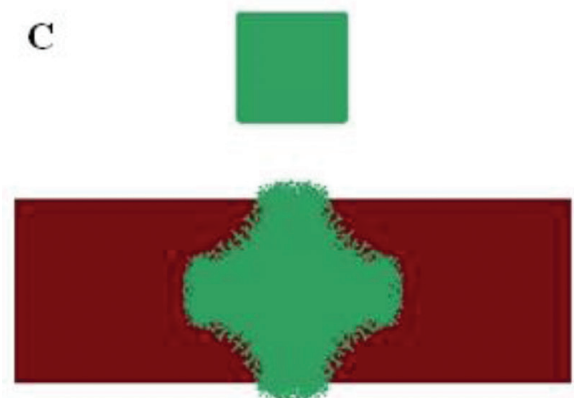

B
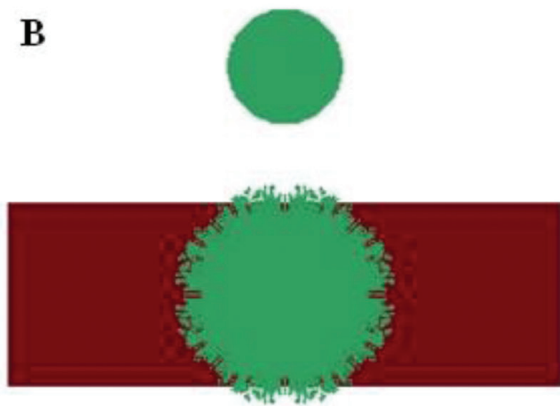

D
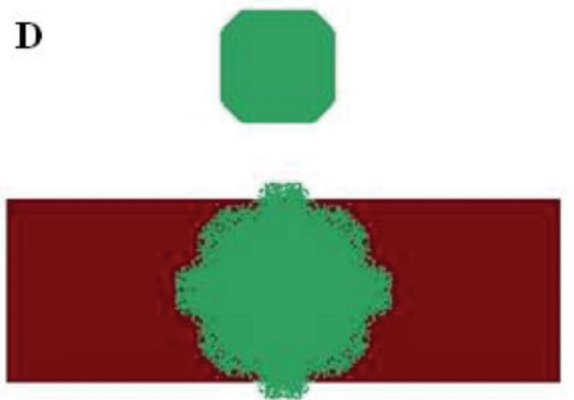

Figure 2: Charge details, plan view of the charge and of the explosive expansion characteristics: A) photograph of the charge, B) cylindrical, C) cube and D) bag.

spherical charges), the surface receiving the explosion and the type of charge. In all tests performed, the charge can be considered as free air. This method is based on the tests of Kingery and Bulmash [11], which were subsequently compiled in the ConWep software. Due to the complexity of the numerical models that involve the SPH formulation, slabs with FRP reinforcement have only been calculated with the LBE-type detonation model.

\section{RESULTS AND DISCUSSION}

The results are analysed from the biggest scaled distance to the lowest one.

\subsection{Scaled distance equal to $0.83 \mathrm{~m} / \mathrm{kg}^{1 / 3}$ : test $\mathrm{S} 1$}

In this test, the pressure of the shock wave affecting the slab due to the detonation of the explosive charge was measured with pressure sensors. However, with the SPH method, it is not possible to measure the pressure exerted by the particles on the Lagrangian model of the slab. This can be done in the LBE model. On the other hand, it is possible to measure the expansion pressure of the explosive in the SPH model, but not in the LBE one. Both are advantages and disadvantages of each of the models used.

In terms of the applied pressure to the slab surface, the P1 sensor recorded a value equal to 2.01 MPa, whereas the LBE model has been $1.98 \mathrm{MPa}$, with a relative error of $1.5 \%$. In the case of SPH, depending on the number of particles used, the pressures generated may vary, as well as the calculation times, which will increase as the number of particles increases. The result of the expansion pressures can be seen in Table 3. These results agree with other previously published values around $10 \mathrm{GPa}$ [22]. 
Table 3: Pressures in SPH models, Slab S1.

\begin{tabular}{lll}
\hline Model & $\mathbf{N}^{\mathbf{0}}$ SPH & Maximum pressure [GPa] \\
\hline FE-SPH1 & 125000 & 9.95 \\
FE-SPH2 & 250000 & 10.12 \\
FE-SPH3 & 500000 & 10.67 \\
FE-SPH4 & 800000 & 11.12 \\
\hline
\end{tabular}

Acceleration values measured in the slab can be calculated with both models. The value recorded with the A2 sensor was equal to $1028.6 \mathrm{~g}$. The errors shown in Table 4 are calculated in comparison with the value measured in the field. With an error of about $5 \%$, the acceleration value for the LBE model is very good. In the case of SPH models, increasing the number of elements brings the obtained acceleration closer to the calculated value with a minimum of about $4 \%$. The difference is that the acceleration values in SPH models are higher than the measured, while the LBE is lower.

The damage produced by the detonation in this case is very superficial and, therefore, not worth analysing.

\subsection{Scaled distance equal to $0.42 \mathrm{~m} / \mathrm{kg}^{1 / 3}$ : test $\mathrm{S} 5, \mathrm{~S} 6 / 8, \mathrm{~S} 7$}

With a smaller scaled distance, it is evident that the damage produced is greater. In this case, it is even possible to measure the surfaces or areas of damage, defined as the ratio between the eroded area and the total area of the slab for each surface. In the numerical model, the damage is calculated as the ratio between the area of eroded or damaged elements versus the total area. Table 5 shows the damage measured in the field test, numerical model and the relative error between them. Note that only the slab S7 has four different numerical models, one with LBE (named FE-LBE in Table 5) and three with SPH (named FE-SPH in Table 5). The three SPH models are composed of 800000 particles, since the previous results reflect that this is a sufficient value to obtain reasonable results. It should be noted that in these cases where the explosive charge was equal to $13.05 \mathrm{~kg}$ of TNT Eq., the shape of the explosive charge could not be categorised into a particular type. Therefore, three different models were made as follows: cylindrical (S7-Cy), cubic (S7-Cu) and bag (S7-B). Note that the bag is constructed as the union between a cube and a sphere.

As can be seen from the data presented in Table 5, RC slabs (S7) show the highest damage. As for the reinforcements used, the glass and carbon FRP reinforcement show very similar results on the blast (top) face (it should be recalled that both reinforcements were placed at

Table 4: Acceleration values in numerical models, Slab S1.

\begin{tabular}{llll}
\hline Model & $\mathbf{N}^{\mathbf{0}}$ SPH & Model acceleration [g] & Error [\%] \\
\hline FE-LBE & - & 975.53 & -5.16 \\
FE-SPH1 & 125000 & 2428.57 & 135.9 \\
FE-SPH2 & 250000 & 2040.82 & 98.2 \\
FE-SPH3 & 500000 & 1275.51 & 23.9 \\
FE-SPH4 & 800000 & 1071.43 & 4.1 \\
\hline
\end{tabular}


Table 5: Damaged area for slabs at $0.42 \mathrm{~m} / \mathrm{kg}^{1 / 3}$.

\begin{tabular}{lllllll}
\hline Slab & Model & Side & $\begin{array}{l}\text { Reinforce- } \\
\text { ment }\end{array}$ & $\begin{array}{l}\text { Experimen- } \\
\text { tal [\%] }\end{array}$ & $\begin{array}{l}\text { LS-DYNA } \\
{[\%]}\end{array}$ & $\begin{array}{l}\text { Rel. error } \\
{[\%]}\end{array}$ \\
\hline S5 & FE-LBE & Top & Glass & 3.89 & 3.66 & -6.02 \\
& & Bottom & & 5.78 & 6.52 & 12.72 \\
\multirow{2}{*}{ S6/S8 } & \multirow{2}{*}{ FE-LBE } & Top & Carbon & $3.27-5.45$ & 3.04 & -6.93 \\
& & Bottom & & $6.71-6.96$ & 6.43 & -7.54 \\
S7 & \multirow{2}{*}{ FE-LBE } & Top & \multirow{2}{*}{ None } & 3.38 & 4.20 & 13.80 \\
& & Bottom & & 10.34 & 10.83 & 4.77 \\
\multirow{2}{*}{ S7-Cy } & \multirow{2}{*}{ FE-SPH } & Top & \multirow{2}{*}{ None } & 3.38 & 3.06 & -9.45 \\
& & Bottom & & 10.34 & 8.97 & -13.24 \\
\multirow{2}{*}{ S7-Cu } & \multirow{2}{*}{ FE-SPH } & Top & \multirow{2}{*}{ None } & 3.38 & 3.10 & -8.28 \\
& & Bottom & & 10.34 & 10.81 & 4.54 \\
\multirow{2}{*}{ S7-B } & \multirow{2}{*}{ FE-SPH } & Top & \multirow{2}{*}{ None } & 3.38 & 2.43 & -28.10 \\
& & Bottom & & 10.34 & 9.48 & -8.36 \\
\hline
\end{tabular}

the opposite side - bottom in Table 5). However, it seems that for this scaled distance, the results of GFRP are slightly better than those presented by CFRP.

As for the numerical models, it can be said that present more than acceptable results. The FE-LBE model presents errors that are below $15 \%$ in the damage area for both faces of the slab, which, considering the non-linear nature of the phenomenon, the working scale, and other limitations, is a great result. On the other hand, the model with SPH has good results when the load is described by a cylinder (S7-Cy) or a cube (S7-Cu). While if we describe the load by a bag, the result for the face that receives the explosion is a little worse, shooting the error up to $30 \%$.

The results in terms of damage shape, for the top side (Fig. 3), are also good for the LBE models, although they perhaps overestimate a little the damage in the slab contour areas. In slab S7 (Fig. 3 - C), the damage shape is good for the LBE and the SPH models with cylinder and cube, not so with the bag, which is not able to damage the centre of the slab, as it happens in the other models and in reality.

On the bottom side (Fig. 4), the results are similar in that the damage shapes resemble the actual results, with an overestimation of damage at the slab edges. The SPH models for slab S7 also show very good results, without as much overestimation at the ends and with damage more spread along the slab. Therefore, we can say that for this scaled distance, the SPH models represent very faithfully the reality, including a fracture pattern more like the one obtained in the tests than the LBE model.

\subsection{Scaled distance equal to $0.21 \mathrm{~m} / \mathrm{kg}^{1 / 3}$ : test $\mathrm{S} 2, \mathrm{~S} 3, \mathrm{~S} 4$}

With this scaled distance, full penetration of the slab occurs, with a hole joining the two surfaces (see Figs. 5 to 8).

The reinforcements used do not always improve the damage surface area on the bottom side (Table 6), as can be observed for GFRP (S3). In this case, and certainly due to poor bonding of the material, the damage area was increased by $4 \%$. However, the CFRP (S4) 

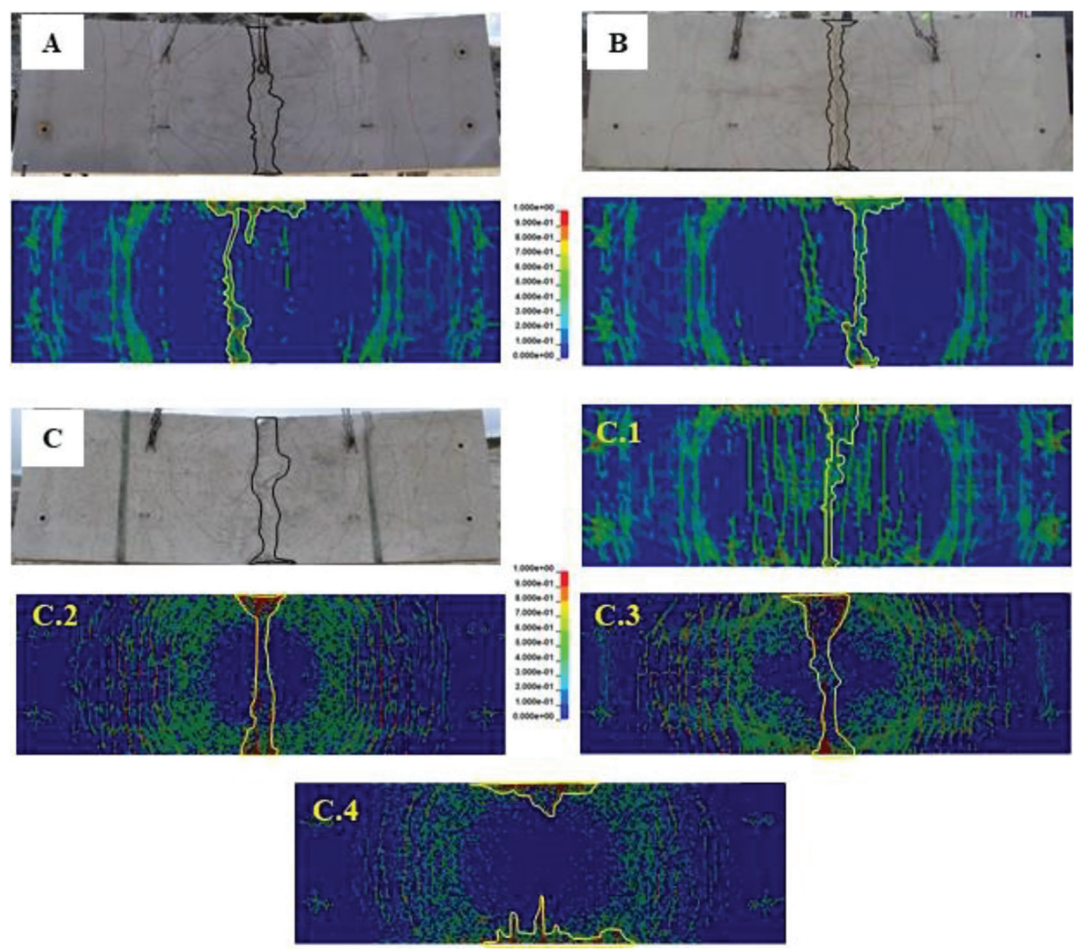

Figure 3: Top damage for slabs: A) S5 and FE-LBE model; B) S8 and FE-LBE model; C) S7 and FE-LBE model (C.1), FE-SPH-Cylinder model (C.2), FE-SPH-Cube model (C.3) and FE-SPH-Bag model (C.4).

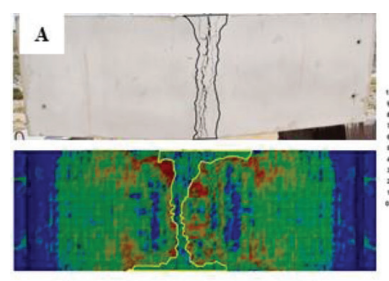

c
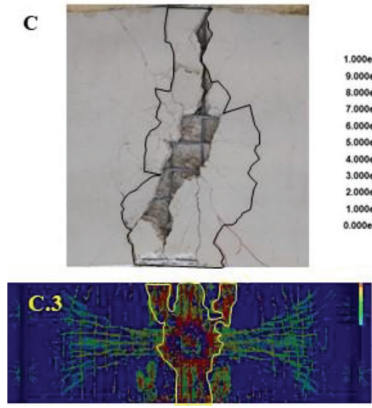

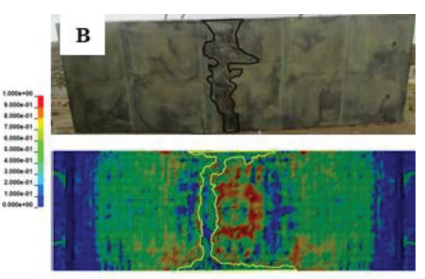

C.1

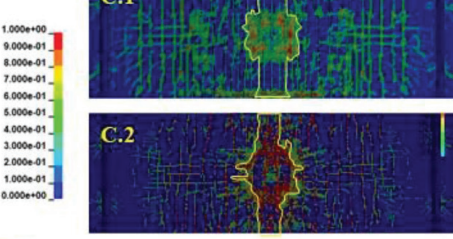

C.4

Figure 4: Bottom damage for slabs: A) S5 and FE-LBE model; B) S8 and FE-LBE model; C) S7 and FE-LBE model (C.1), FE-SPH-Cylinder model (C.2), FE-SPH-Cube model (C.3) and FE-SPH-Bag model (C.4). 

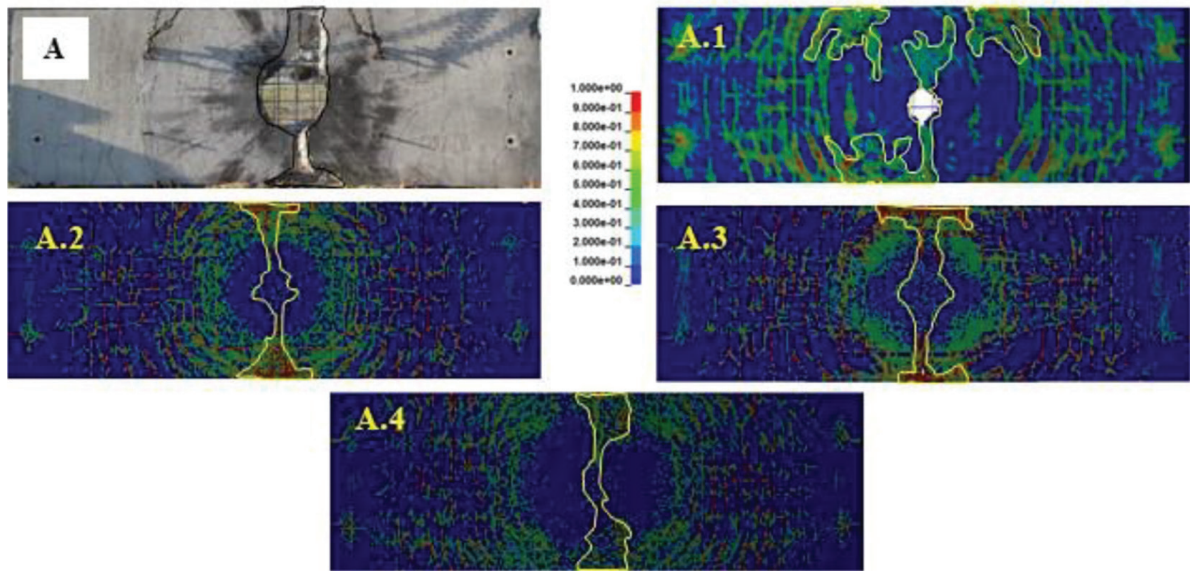

Figure 5: Top damage for slab S2 (A), FE-LBE model (A.1), FE-SPH-Cylinder model (A.2), FE-SPH-Cube model (A.3) and FE-SPH-Bag model (A.4).
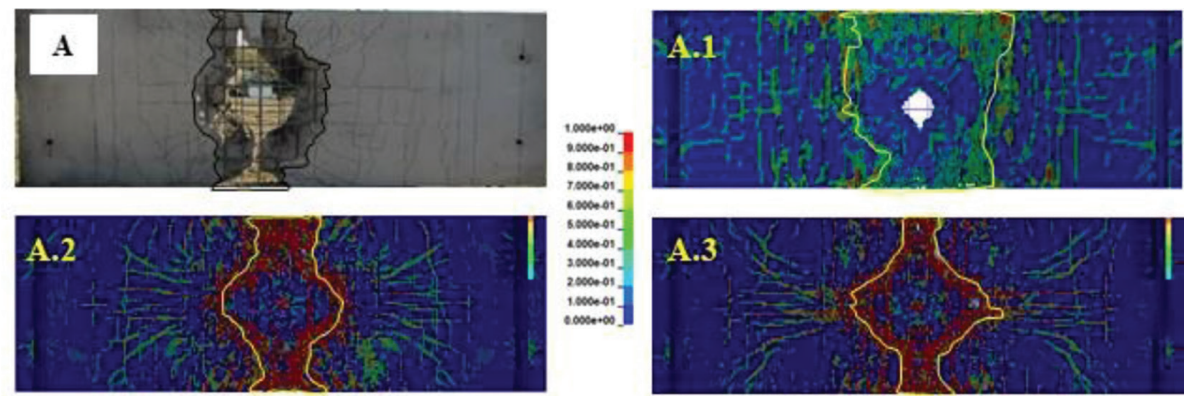

10000001

2000001

20000091
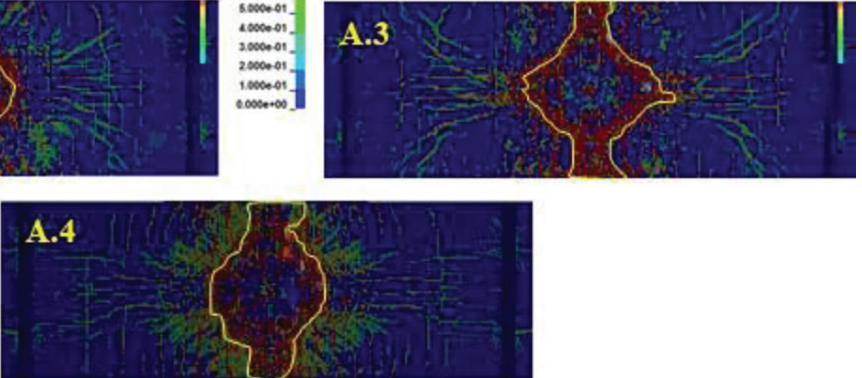

Figure 6: Bottom damage for slab S2(A), FE-LBE model (A.1), FE-SPH-Cylinder model (A.2), FE-SPH-Cube model (A.3) and FE-SPH-Bag model (A.4).
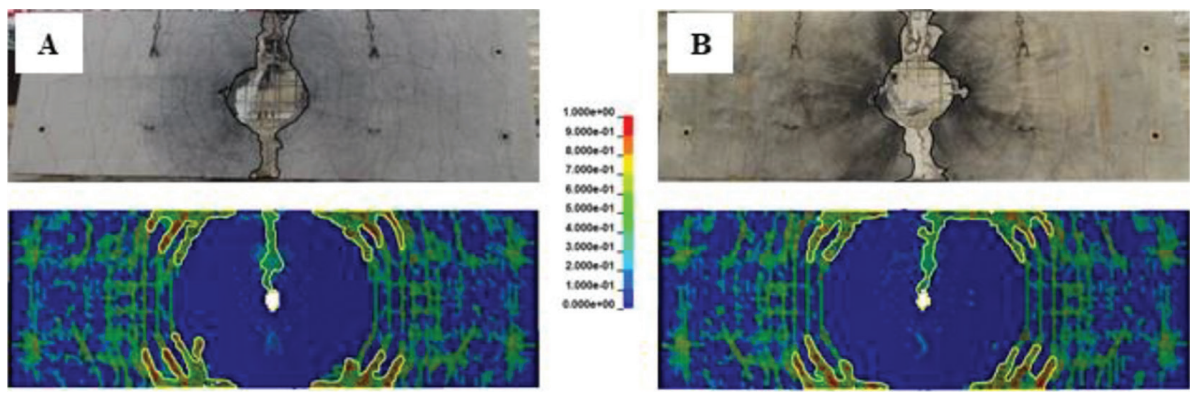

Figure 7: Top damage for slabs: A) S3 and FE-LBE model and B) S4 and FE-LBE. 

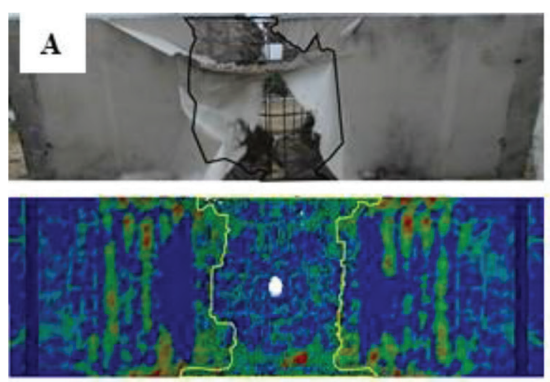
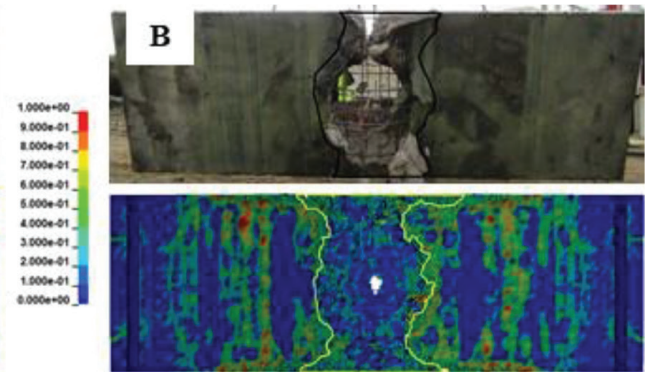

Figure 8: Bottom damage for slabs: A) S3 and FE-LBE model and B) S4 and FE-LBE.

Table 6: Damaged area for slabs at $0.21 \mathrm{~m} / \mathrm{kg}^{1 / 3}$.

\begin{tabular}{lllllll}
\hline Slab & Model & Side & $\begin{array}{l}\text { Reinforce- } \\
\text { ment }\end{array}$ & $\begin{array}{l}\text { Experimen- } \\
\text { tal [\%] }\end{array}$ & $\begin{array}{l}\text { LS-DYNA } \\
{[\%]}\end{array}$ & $\begin{array}{l}\text { Rel. error } \\
{[\%]}\end{array}$ \\
\hline S2 & FE-LBE & Top & None & 8.19 & 8.48 & 3.55 \\
& & Bottom & & 18.62 & 17.63 & -5.35 \\
\multirow{2}{*}{ S2-Cy } & \multirow{2}{*}{ FE-SPH } & Top & None & 8.19 & 4.90 & -40.25 \\
& & Bottom & & 18.62 & 16.23 & -12.84 \\
S2-Cu & FE-SPH & Top & \multirow{2}{*}{ None } & 8.19 & 6.04 & -26.29 \\
& & Bottom & & 18.62 & 17.42 & -6.45 \\
S2-B & \multirow{2}{*}{ FE-SPH } & Top & \multirow{2}{*}{ None } & 8.19 & 5.18 & -36.77 \\
& & Bottom & & 18.62 & 18.22 & -2.15 \\
S3 & \multirow{2}{*}{ FE-LBE } & Top & Glass & 7.63 & 6.96 & -8.72 \\
& & Bottom & & 22.48 & 22.85 & 1.66 \\
S4 & \multirow{2}{*}{ FE-LBE } & Top & Carbon & 7.83 & 7.54 & -3.64 \\
& & Bottom & & 16.78 & 19.59 & 16.74 \\
\hline
\end{tabular}

reinforcement improves the damage surface by $2 \%$. In both cases, the face that receives the explosion, which works under compression, shows better results. The improvements are in any case slight, and more tests would be necessary to consider these solutions as verified solutions or fully tested ones.

The numerical models work well in practically all cases (Table 6), however, what was evidenced for the scaled distance equal to $0.42 \mathrm{~m} / \mathrm{kg}^{1 / 3}$ cannot be stated here. The FE-LBE models perform very well, with errors limited to around $15 \%$, with an average of $6.6 \%$ in absolute value. Even these models can simulate the slab hole. On the contrary, the FE-SPH models do not present such good results in terms of damage area, nor the slab hole, although they do represent the aspect of surface damage and cracking. Perhaps the model that globally presents better results is the FE-SPH model of the cube (S2-Cu), while the model of the bag (S2-B) fits very well the area (and shape) of damage at the bottom of the slab. 


\section{CONCLUSIONS}

This study shows the development of several numerical models to describe full-scaled 3D RC slabs. Although more tests are needed, the results of the glass and carbon fibre reinforcements are promising in terms of reducing damage and spalling in concrete. It should be noted that in the case of GF, there may be problems in the bonding of the reinforcement, affecting its performance and, therefore, the results.

Numerical models with the load description as LBE or SPH perform remarkably well for scaled distances of 0.83 and $0.42 \mathrm{~m} / \mathrm{kg}^{1 / 3}$. For smaller scaled distances, $0.21 \mathrm{~m} / \mathrm{kg}^{1 / 3}$, the LBE model still performs very well. In contrast, the SPH model is not able to perforate the slab nor to reproduce the area of the damage done. Perhaps the number of particles should be higher, but time and available computational capacity make it impossible to increase this number. Therefore, it can be said that the FE-SPH models work well up to scaled distances in the average field although for the near field they have not performed as well.

\section{ACKNOWLEDGEMENTS}

This research has been conducted under the PICAEX project funded by the Centre for Industrial Technological Development (CDTI), an agency of the Spanish Government. We would like to thank all the people from TAPUSA, MAPEI and FHECOR who contributed to the design and execution of the tests. We also thank the staff in La Marañosa (ITM-INTA) for their help at the testing site.

\section{REFERENCES}

[1] Zhang, C. \& Mousavi, A.A., Blast loads induced responses of RC structural members: State-of-the-art review. Composites Part B: Engineering, 195, p. 108066, 2020. https:// doi.org/10.1016/j.compositesb.2020.108066

[2] Thai, D.K., Nguyen, D.L., Pham, T.H. \& Doan, Q.H., Prediction of residual strength of FRC columns under blast loading using the FEM method and regression approach. Construction and Building Materials, 276, p. 122253, 2021. https://doi.org/10.1016/j. conbuildmat.2021.122253

[3] Castedo, R., Segarra, P., Alañón, A., Lopez, L.M., Santos, A.P., \&Sanchidrian, J.A., Air blast resistance of full-scale slabs with different compositions: Numerical modeling and field validation. International Journal of Impact Engineering, 86, pp. 145-156, 2015. https://doi.org/10.1016/j.ijimpeng.2015.08.004

[4] Badshah, E., Naseer, A., Ashraf, M., Shah, F. \& Akhtar, K., Review of blast loading models, masonry response, and mitigation. Shock and Vibration, 2017.

[5] Lantz, L., Maynez, J., Cook, W. \& Wilson, C.M.D., Blast protection of unreinforced masonry walls: A state-of-the-art review. Advances in Civil Engineering, 2016.

[6] Bermejo, M., Santos, A.P., \& Goicolea, J.M., Development of practical finite element models for collapse of reinforced concrete structures and experimental validation. Shock and Vibration, 4636381, 2017.

[7] Terranova, B., Whittaker, A. \&Schwer, L., Design of concrete walls and slabs for windborne missile loadings. Engineering Structures, 194, pp. 357-69, 2019. https://doi. org/10.1016/j.engstruct.2019.05.001

[8] Kumar, V., Kartik, K.V. \& Iqbal, M.A., Experimental and numerical investigation of reinforced concrete slabs under blast loading. Engineering Structures, 206, p. 110125, 2020. https://doi.org/10.1016/j.engstruct.2019.110125 
[9] Livermore Software Technology Corporation (LSTC). LS-DYNA Keyword User's Manual - R11 2018:3186.

[10] ANSYS. AUTODYN User Manual Version 15.0 2013.

[11] Kingery, C. \&Bulmash, G., Airblast parameters from TNT spherical air burst and hemispherical surface burst. US Army Armament and Development Center, Ballistic Research Laboratory, 1984.

[12] Chiquito, M., Castedo, R., López, L.M., Santos, A.P., Mancilla, J.M., \&Yenes, J.I., Blast wave characteristics and TNT equivalent of improvised explosive device at small scaled distances. Defence Science Journal, 69(4), pp. 328-335, 2019. https://doi.org/ $10.14429 /$ dsj.69.13637

[13] UFC 3-340-02. Structures to resist the effects of accidental explosions. US Department of the Army, Navy and Air Force Technical Manual, 2008.

[14] Gomathi, K.A., Rajagopal, A., Reddy, K.S.S. \& Ramakrishna, B., Plasticity based material model for concrete subjected to dynamic loadings. International Journal of Impact Engineering, 142, p. 103581, 2020. https://doi.org/10.1016/j.ijimpeng.2020.103581

[15] Tai, Y.S., Chu, T.L., Hu, H.T. \& Wu, J.Y., Dynamic response of a reinforced concrete slab subjected to air blast load. Theoretical and Applied Fracture Mechanics, 56(3), pp. 140-147, 2011. https://doi.org/10.1016/j.tafmec.2011.11.002

[16] UNE-EN 1992-1-1:2013: Eurocode 2: Design of concrete structures - Part 1-1: General rules and rules for buildings, 2013.

[17] Castedo, R., Santos, A.P., Alañón, A., Reifarth, C., Chiquito, M., López, L.M., MartínezAlmajano, S. \& Pérez-Caldentey, A., Numerical study and experimental tests on fullscale RC slabs under close-in explosions. Engineering Structures, 231, p. 111774, 2021. https://doi.org/10.1016/j.engstruct.2020.111774

[18] Alañón, A., Cerro-Prada, E., Vázquez-Gallo, M.J., \& Santos, A.P., Mesh size effect on finite-element modeling of blast-loaded reinforced concrete slab. Engineering with Computers, 34(4), pp. 649-658, 2018. https://doi.org/10.1007/s00366-017-0564-4

[19] Hashin, Z., Failure criteria for unidirectional fiber composites. Journal of Applied Mechanics, 180, pp. 329-334, 1980. https://doi.org/10.1115/1.3153664

[20] García, C.R., Modelización de losas de hormigón armado frente a explosiones. Universidad Politécnica de Madrid, 2020.

[21] Cherniaev, A., Montesano, J., \& Butcher, C., Modeling the axial crush response of CFRP tubes using MAT054, MAT058 and MAT262 in LS-DYNA®. In Proceedings of the 15th International LS-DYNA® Users Conference, Detroit, MI, USA, pp. 10-12, 2018.

[22] Li, J., Wu, C., Hao, H., \& Su, Y., Experimental and numerical study on steel wire mesh reinforced concrete slab under contact explosion. Materials \& Design, 116, pp. 77-91, 2017. https://doi.org/10.1016/j.matdes.2016.11.098 